\title{
Chronic kidney disease and risk factor prevalence in Saint Kitts and Nevis: a cross-sectional study
}

\author{
Deidra C. Crews ${ }^{1,2^{*}}$, Kirk N. Campbell ${ }^{3}$, Yang Liu ${ }^{1,2}$, Odell Bussue ${ }^{4}$, Ingrid Dawkins ${ }^{4}$ and Bessie A. Young ${ }^{5}$
}

\begin{abstract}
Background: The prevalence of chronic kidney disease (CKD) in St. Kitts and Nevis, islands of the West Indies, is unknown. We sought to determine estimates of CKD and its risk factors (e.g. diabetes, hypertension and obesity) in St. Kitts and Nevis.

Methods: This was a chronic disease screening program. Three community-based locations in St. Kitts and Nevis were included in the program. Participants were adult community residents aged $\geq 18$ years. The main outcome measures were estimated CKD prevalence (by serum creatinine-based estimated glomerular filtration rate (eGFR) and dipstick urine albumin); and estimated prevalence of CKD risk factors (diabetes, hypertension and obesity). Logistic regression was used to determine independent predictors of CKD.

Results: One thousand nine hundred seventy eight persons, from Nevis $(n=950)$ and St. Kitts $(n=1028)$ were screened by the Caribbean Health and Education Foundation. Participants' mean age was $49 \pm 15$ years, $65 \%$ were female, and $99 \%$ were black. Fully, 21.5\% had diabetes and $53.1 \%$ had hypertension; and $40.3 \%$ were obese. Mean estimated eGFR was $98 \mathrm{ml} / \mathrm{min} / 1.73 \mathrm{~m}^{2}$ (standard deviation = 30) and $4.7 \%$ had an eGFR $<60 \mathrm{ml} / \mathrm{min} / 1.73 \mathrm{~m}^{2}$, indicating CKD. Age [Odds Ratio $(O R)=1.08,95 \%$ Confidence Interval $(C I) 1.05-1.11$ ], hypertension $(\mathrm{OR}=2.89,95 \%$ $\mathrm{Cl} 1.18-7.07)$ and diabetes $(\mathrm{OR}=3.12,95 \% \mathrm{Cl} 1.80-5.43)$ were independent predictors of reduced eGFR in models adjusted for age, gender and obesity status. Of those with urine testing in Nevis ( $n=929), 13.5 \%$ had urine albumin $\geq 30 \mathrm{mg} / \mathrm{dL}$, and diabetes was an independent predictor of this finding ( $\mathrm{OR}=2.43,95 \% \mathrm{Cl} 1.53-3.87)$.
\end{abstract}

Conclusions: CKD and its risk factors were prevalent among adults in St. Kitts and Nevis. Public policy strategies for prevention and treatment of these conditions may be needed to reduce their associated morbidity, mortality and costs.

Keywords: Chronic kidney disease, Epidemiology, Risk factors, Diabetes, Hypertension

\section{Background}

Non-communicable chronic diseases such as stroke, heart disease, diabetes, and hypertension are the leading causes of death in the member countries of the Organization of Eastern Caribbean States (which includes Antigua and Barbuda, Commonwealth of Dominica, Grenada, Montserrat, St. Kitts and Nevis, St. Lucia and St. Vincent and the Grenadines), like that of the wider region,

\footnotetext{
* Correspondence: dcrews1@jhmi.edu

${ }^{1}$ Division of Nephrology, Department of Medicine, Johns Hopkins University School of Medicine, 301 Mason F. Lord Drive, Suite 2500, Baltimore, MD 21224, USA

${ }^{2}$ Welch Center for Prevention Epidemiology and Clinical Research, Johns Hopkins Medical Institutions, Baltimore, MD, USA

Full list of author information is available at the end of the article
}

accounting for over half of deaths [1]. Diabetes and hypertension are the two major causes of chronic kidney disease (CKD) and end stage renal disease (ESRD) worldwide [2]. Reports from the Caribbean Renal Registry (CRR) also indicate diabetes and hypertension are the leading causes of CKD and ESRD in the Caribbean [2,3]. Little is known regarding the prevalence of $\mathrm{CKD}$ in the Caribbean, particularly in St. Kitts and Nevis.

The Federation of St. Kitts and Nevis, also known as the Federation of Saint Christopher and Nevis, is a two-island country in the West Indies. The capital city is Basseterre on the larger island of St. Kitts and the smaller island of Nevis lies about 2 miles $(3 \mathrm{~km})$ southeast of St. Kitts. Persons residing on St. Kitts 
(population approximately 45,000) have somewhat greater access to goods and services than those on Nevis (population approximately 12,000), although they share similar sociodemographic compositions.

The Caribbean Health and Education Foundation (CHEF) proposed and conducted a screening program for CKD, diabetes, and hypertension to ascertain the prevalence of CKD and major CKD risk factors in St. Kitts and Nevis. The major objective of CHEF's Caribbean Kidney Screening and Education Program (CKSEP) was to provide rapid CKD screening among adults who are at risk of developing CKD due to personal and/or family history of diabetes, hypertension or CKD and inform these individuals about $C K D$, enabling them to better manage their risk. In this manuscript, we report estimates of CKD and its risk factors (e.g. diabetes, hypertension and obesity) as assessed during the CKSEP in St. Kitts and Nevis.

\section{Methods}

\section{Setting and collaboration}

CHEF collaborated with the Nevis Renal Society, the St. Kitts Diabetic Association and The Kidney Trust Foundation to execute the CKSEP, utilizing The Kidney Trust Foundation's rapid CKD screening program model to assist in identifying people with increased risk of developing CKD and ESRD, and educate/empower them to better manage their illnesses. CKSEP took place on the islands of Nevis and St. Kitts on March 17-18 and March 20-21, 2014, respectively. Three visiting nephrologists, in collaboration with local primary care physicians and a local nephrologist, provided on-site individual consultation to participants at the screenings in Nevis and St. Kitts. The nephrologists and primary care providers were joined by nurses, phlebotomists, medical students and lab technician volunteers. Other volunteers were recruited for registration of individuals, assistance with guiding participants through the screening process, and crowd management.

\section{Participants}

The CKSEP was advertised for several weeks on local radio, television and at community-based clinics as an opportunity for individuals with risk factors for CKD (diabetes, hypertension and/or obesity) to be screened. Adults $\geq 18$ years of age were eligible. Otherwise, there were no exclusions. All participants provided written consent for screening.

\section{Measurements}

Participants were asked sociodemographic questions (age, gender, race/ethnicity), and were asked about their personal (self-report) and family history of diabetes, hypertension and kidney disease, and the name of their regular physician. During the screening, the CKSEP team assessed participants' height, weight [for body mass index (BMI) (weight/height ${ }^{2}$ ) calculation], and seated systolic and diastolic blood pressure $(\mathrm{mmHg})$ using automated cuffs. BMI 25 to $29.9 \mathrm{~kg} / \mathrm{m}^{2}$ was considered overweight, and $\geq 30 \mathrm{~kg} / \mathrm{m}^{2}$ was considered obesity. Systolic blood pressure $\geq 140 \mathrm{mmHg}$ or diastolic blood pressure $\geq 90 \mathrm{mmHg}$ were considered diagnostic of hypertension.

A venous blood sample for each participant was processed directly on site, using i-STAT Portable Clinical Analyzer (Abbott Laboratories, Abbott Park, IL, USA), which performs rapid blood analysis and displays quantitative test results in approximately 3-5 min. Calibration is automatically performed as part of the iSTAT System test cycle. Quality assurance/performance of the iSTAT System (as performed by The Kidney Trust staff) was verified using the internal or external electronic simulator every $24 \mathrm{~h}$ of testing. Serum creatinine was assessed using i-STAT. Estimated glomerular filtration rate (eGFR) was calculated using the 4 variable Modification of Diet in Renal Disease study equation [4] and used to determine stage of CKD [5]. Estimated GFR $<60 \mathrm{ml} /$ $\mathrm{min} / 1.73 \mathrm{~m}^{2}$ was considered to define reduced eGFR. Random serum glucose was assessed by fingerstick samples using commercially available glucometers (Contour Next and Precision Xtra). Non-fasting fingerstick glucose at or exceeding $200 \mathrm{mg} / \mathrm{dL}$ was considered diagnostic of diabetes mellitus [6]. Urine dipsticks were used to assess evidence of albuminuria (Siemens Multistix 10 SG and Siemens CLINITEK Microalbumin 2). Urine albumin results were reported as 0 -trace, $30-100 \mathrm{mg} / \mathrm{dL}$, $100-300 \mathrm{mg} / \mathrm{dL}$, and $>300 \mathrm{mg} / \mathrm{dL}$. Values 30 and above were considered as evidence of albuminuria. Due to limited availability of urine dipsticks, only high risk participants in Nevis (i.e. those with known diabetes or hypertension) underwent screening for albuminuria.

\section{Data analysis}

Screening data were initially recorded on paper forms and later entered into an electronic database. Data were analyzed individually and together for both St. Kitts and Nevis. Comparisons were also made between islands. Means and proportions for demographic and clinical variables were obtained using t-tests and chi squared tests where appropriate. Serum glucose and blood pressure were described continuously, and as binary variables (yes/no for diabetes or hypertension). Overweight and obesity were each described categorically. Estimated GFR was described continuously and in categories and stages of CKD. Albuminuria was described categorically. Multivariable logistic regression was used to examine the direction, magnitude and independence of the 
associations of demographic and clinical variables with prevalent reduced eGFR (defined as $<60 \mathrm{ml} / \mathrm{min}$ per $1.73 \mathrm{~m}^{2}$ ) or albuminuria. In the regression models, age was modeled continuously, while all other covariates were modeled as binary variables.

\section{Results}

A total of 1978 presented to the screening programs on the islands of Nevis and St. Kitts and underwent screening. In Nevis, 950 participants were screened at the Anglican Church Hall in Charlestown. In St. Kitts, 1028 participants were screened at two venues, which operated simultaneously - Newtown and McKnight Community Centers in Basseterre.

\section{Screening findings in Nevis}

The participants screened in Nevis represented approximately $8 \%$ of the total population, which is approximately 12,000. The overwhelming majority of participants were English-speaking. Those speaking Spanish or Saint Kitts Creole were able to be accommodated by the language skills of the screening team. The mean age was 49 years, and the majority of participants were female (64\%). The overwhelming majority of participants were of black race (Table 1). Many individuals screened had risk factors for CKD, including $28 \%$ who self-reported a diagnosis of hypertension and $16.8 \%$ who reported having diabetes. Additionally, the average systolic blood pressure of the screened population fell in the 'stage 1 hypertension' range [7]. Notably, $8.2 \%$ of participants who underwent serum glucose testing had a value exceeding $200 \mathrm{mg} / \mathrm{dL}$, and 12 (17.1\%) of these individuals were unaware of a diagnosis of diabetes (based on their answers to our screening questionnaire). The majority of participants were found to be either overweight (38\%) or obese (38\%). Overweight and obesity were more prevalent among females, with females comprising $62 \%$ of overweight and $75 \%$ of obese persons screened.

\section{Screening findings in St. Kitts}

The 1028 persons screened in St. Kitts represented approximately $2 \%$ of the total population, which is estimated to be 45,000 . Similar to Nevis, participants were a mean age of 49 years, the majority were female (66\%), and the overwhelming majority were of black race (Table 1). A total of $36 \%$ self-reported a diagnosis of hypertension and $23.6 \%$ reported having diabetes. Additionally, the average systolic blood pressure of the screened population fell in the 'pre-hypertension' range. Fully, 9.5\% of participants who underwent serum glucose testing had a value that exceeded $200 \mathrm{mg} / \mathrm{dL}$, and $11(17.5 \%)$ of these individuals were unaware of a diagnosis of diabetes. The majority of participants assessed ( $n=590)$ were found to be either overweight $(32 \%)$ or obese (44\%). Overweight and obesity were more prevalent among females, with females comprising 56\% of overweight and $76 \%$ obese persons screened.

\section{Kidney disease in Nevis and St. Kitts}

Among the kidney disease measures administered, persons were found to have a mean eGFR of $98 \mathrm{~mL} / \mathrm{min} /$ $1.73 \mathrm{~m}^{2}$ (SD) and $4.7 \%$ had an eGFR $<60 \mathrm{~mL} / \mathrm{min} /$ $1.73 \mathrm{~m}^{2}$. Nevisians had a lower average eGFR than Kittitians screened, but there were no differences in the prevalence of eGFR $<60 \mathrm{ml} / \mathrm{min}$ per $1.73 \mathrm{~m}^{2}$. The majority of participants $(88 \%)$ with an eGFR $<60 \mathrm{~mL} / \mathrm{min} / 1.73 \mathrm{~m}^{2}$ would be considered to have CKD stage 3 by National Kidney Foundation guidelines if confirmed on repeat analyses [5]. Eleven persons had more advanced CKD (eGFR $<30$ / CKD stages 4 and 5). A total of 929 Nevisians underwent urine testing, and 126 individuals (13.5\%) had a urine albumin level of at least $30 \mathrm{mg} / \mathrm{dL}$, which is suggestive of kidney damage. Five persons screened $(0.5 \%)$ had significantly elevated urine albumin (of at least $300 \mathrm{mg} / \mathrm{dL}$ ) (Table 2). Due to a limited supply of dipsticks, only 183 participants underwent screening for urine albumin in St. Kitts. These were primarily persons with risk factors for CKD (e.g. diabetes), and/or those identified to have reduced eGFR during screening. Among them, 141 individuals had a urine albumin of at least $30 \mathrm{mg} / \mathrm{dL}$. Eleven persons screened in St. Kitts had significantly elevated urine albumin (of at least $300 \mathrm{mg} / \mathrm{dL}$ ).

Independent predictors of eGFR $<60 \mathrm{ml} / \mathrm{min}$ per $1.73 \mathrm{~m}^{2}$ in the overall population (both islands), included age, self-reported and/or measured hypertension and self-reported and/or lab-confirmed diabetes mellitus (Table 3). Similar predictors were observed for both St. Kitts and Nevis, however, hypertension was not a statistically significant predictor of reduced eGFR in St. Kitts following adjustment for obesity. Diabetes (self-reported and/or lab-confirmed) was the only observed independent predictor of albuminuria in Nevis.

\section{Discussion}

In the context of a screening program, we found that CKD and its risk factors were prevalent among adults in St. Kitts and Nevis, including $4.7 \%$ with reduced kidney function and (in Nevis) 13.5\% with albuminuria. Diabetes, hypertension and obesity were highly prevalent in this population, suggesting opportunities for CKD prevention through early detection and evidence-based treatment of these chronic conditions.

There is limited information available from the Caribbean Renal Registry regarding CKD prevalence in the Englishspeaking Caribbean. These data were not derived from population-based screens, but rather were documented by some participating providers of care delivered to their specific patients. For example, in Jamaica there are a reported 
Table 1 Participant characteristics and diabetes, hypertension and obesity screening findings among adults in St. Kitts and Nevis, overall and by island

\begin{tabular}{|c|c|c|c|c|c|c|c|}
\hline Characteristic/finding & All participants & Results for all & $\begin{array}{l}\text { Number of Nevis } \\
\text { participants assessed }\end{array}$ & Nevis results & $\begin{array}{l}\text { Number of St. Kitts } \\
\text { participants assessed }\end{array}$ & St. Kitts results & $P^{*}$ \\
\hline \multicolumn{8}{|l|}{ Demographics } \\
\hline Age in years, mean (SD) & 1978 & $49(15)$ & 950 & $49(15)$ & 1028 & $49(15)$ & 0.69 \\
\hline Age category, $n(\%)$ & 1978 & & 950 & & 1028 & & 0.06 \\
\hline$<40$ years & & $541(27)$ & & $252(26.5)$ & & $289(28.1)$ & \\
\hline $40-49$ years & & $401(20)$ & & $217(22.8)$ & & $184(17.9)$ & \\
\hline $50-59$ years & & $528(27)$ & & $248(26.1)$ & & $280(27.2)$ & \\
\hline$\geq 60$ years & & $508(26)$ & & $233(24.5)$ & & $275(26.8)$ & \\
\hline Female gender, $n(\%)$ & 1978 & $1285(65)$ & 950 & $609(64)$ & 1028 & $676(66)$ & 0.44 \\
\hline Race/ethnicity, n (\%) & 1978 & & 950 & & 1028 & & 0.14 \\
\hline Black & & 1964 (99.3) & & $939(98.8)$ & & $1025(99.7)$ & \\
\hline White & & $5(0.3)$ & & $4(0.4)$ & & $1(0.1)$ & \\
\hline Hispanic & & $9(0.5)$ & & $7(0.7)$ & & $2(0.2)$ & \\
\hline \multicolumn{8}{|l|}{ Chronic Kidney Disease Risk Factors } \\
\hline $\begin{array}{l}\text { Systolic blood pressure, } \\
\text { mean (SD) }\end{array}$ & 1971 & $138(66)$ & 950 & $140(63)$ & 1021 & $136(68)$ & 0.13 \\
\hline $\begin{array}{l}\text { Systolic blood pressure, } \\
\geq 140 \mathrm{mmHg}, n(\%)\end{array}$ & 1971 & $761(38.6)$ & 950 & $412(43.4)$ & 1021 & $349(34.2)$ & $<0.001$ \\
\hline $\begin{array}{l}\text { Diastolic blood pressure, } \\
\text { mean (SD) }\end{array}$ & 1964 & $79(15)$ & 944 & $82(13)$ & 1020 & $76(15)$ & $<0.001$ \\
\hline $\begin{array}{l}\text { Diastolic blood pressure, } \\
\geq 90 \mathrm{mmHg}, n(\%)\end{array}$ & 1964 & $406(20.7)$ & 944 & $239(25.3)$ & 1020 & $167(16.4)$ & $<0.001$ \\
\hline $\begin{array}{l}\text { Self-reported hypertension, } \\
n(\%)\end{array}$ & 1978 & $637(32)$ & 950 & $267(28)$ & 1028 & $370(36)$ & $<0.001$ \\
\hline $\begin{array}{l}\text { Self-reported or measured } \\
\text { hypertension, } n(\%)\end{array}$ & 1978 & $1050(53.1)$ & 950 & $527(56)$ & 1028 & $523(50.9)$ & 0.04 \\
\hline $\begin{array}{l}\text { Serum glucose in } \mathrm{mg} / \mathrm{dL} \text {, } \\
\text { mean (SD) }\end{array}$ & 1518 & $127(64)$ & 857 & $128(60)$ & 661 & $125(69)$ & 0.44 \\
\hline $\begin{array}{l}\text { Serum glucose } \geq 200 \mathrm{mg} / \mathrm{dL} \text {, } \\
n(\%)\end{array}$ & 1518 & $133(8.8)$ & 857 & $70(8.2)$ & 661 & $63(9.5)$ & 0.35 \\
\hline $\begin{array}{l}\text { Self-reported diabetes mellitus, } \\
n(\%)\end{array}$ & 1978 & $403(20.4)$ & 950 & $160(16.8)$ & 1028 & $243(23.6)$ & $<0.001$ \\
\hline $\begin{array}{l}\text { Self-reported or lab-confirmed } \\
\text { diabetes mellitus, } n(\%)\end{array}$ & 1978 & $426(21.5)$ & 950 & $172(18.1)$ & 1028 & $254(24.7)$ & $<0.001$ \\
\hline $\begin{array}{l}\text { Overweight } \\
\left.\text { (BMI } 25 \text { to } 29.9 \mathrm{~kg} / \mathrm{m}^{2}\right), n \text { (\%) }\end{array}$ & 1494 & $529(35.4)$ & 904 & $340(37.6)$ & 590 & $189(32.0)$ & 0.03 \\
\hline Obesity (BMI $\left.\geq 30 \mathrm{~kg} / \mathrm{m}^{2}\right), n(\%)$ & 1494 & $602(40.3)$ & 904 & $345(38.2)$ & 590 & $257(43.6)$ & 0.04 \\
\hline
\end{tabular}

Abbreviations: $S D$ standard deviation, $n$ number of individual participants, $B M I$ body mass index

*P values indicate whether findings on Nevis versus St. Kitts were statistically significantly different

968 patients (population 2.8 million) with CKD, which includes 576 patients on dialysis [8]. Trinidad and Tobago (population 1.2 million) reported 564 patients on dialysis. Diabetes and hypertension are the main causes of ESRD in the English-speaking Caribbean as in the US. In Trinidad and Tobago, Antigua and Barbuda and the British Virgin Islands, diabetes is the primary cause of CKD $(30.5,44$ and $56 \%$ respectively) with hypertension second (16.5, 23.3 and
$28 \%$ respectively) [3]. In Jamaica and St. Lucia hypertension is the most common etiology of CKD (35.2 and 53.3\% respectively) followed by diabetes (29.7 and $25.5 \%$ respectively) [3]. The high prevalence of diabetes and hypertension in St. Kitts/Nevis therefore increases the risk of CKD in this population.

We detected a greater self-reported diabetes prevalence than previously documented by the Pan American 
Table 2 Kidney disease screening findings among adults in St. Kitts and Nevis, overall and by island

\begin{tabular}{|c|c|c|c|c|c|c|c|}
\hline Characteristic/Finding & $\begin{array}{l}\text { All participants } \\
N\end{array}$ & Results for all & $\begin{array}{l}\text { Number of Nevis } \\
\text { participants assessed }\end{array}$ & Nevis results & $\begin{array}{l}\text { Number of St. Kitts } \\
\text { participants assessed }\end{array}$ & $\begin{array}{l}\text { St. Kitts } \\
\text { results }\end{array}$ & $P^{*}$ \\
\hline \multicolumn{8}{|l|}{ Kidney Disease Measures } \\
\hline $\begin{array}{l}\text { Serum creatinine in } \mathrm{mg} / \mathrm{dL} \text {, } \\
\text { mean (SD) }\end{array}$ & 1978 & $0.9(0.3)$ & 950 & $0.9(0.3)$ & 1028 & $0.9(0.4)$ & 0.04 \\
\hline $\begin{array}{l}\text { Estimated GFR }\left(\mathrm{mL} / \mathrm{min} / 1.73 \mathrm{~m}^{2}\right) \\
\text { mean (SD) }\end{array}$ & 1978 & $98(30)$ & 950 & $95(30)$ & 1028 & $100(29)$ & $<0.001$ \\
\hline $\begin{array}{l}\text { Estimated GFR }<60 \mathrm{~mL} / \mathrm{min} / 1.73 \mathrm{~m}^{2} \text {, } \\
n(\%)\end{array}$ & 1978 & $93(4.7)$ & 950 & $44(4.6)$ & 1028 & $49(4.8)$ & 0.89 \\
\hline $\begin{array}{l}\text { Estimated GFR }<45 \mathrm{~mL} / \mathrm{min} / 1.73 \mathrm{~m}^{2} \text {, } \\
n(\%)\end{array}$ & 1978 & $32(1.6)$ & 950 & $18(1.9)$ & 1028 & $14(1.4)$ & 0.35 \\
\hline $\begin{array}{l}\text { CKD stage, } n(\%) \text { [among persons } \\
\text { with estimated GFR < 60] }\end{array}$ & 93 & - & - & - & - & - & 0.87 \\
\hline -Stage 3 (estimated GFR 30 to 59) & & $82(88.2)$ & - & $38(86.4)$ & - & $44(90)$ & \\
\hline -Stage 4 (estimated GFR 15-29) & & $9(9.7)$ & - & $5(11.4)$ & - & $4(8)$ & \\
\hline -Stage 5 (estimated GFR <15) & & $2(2.2)$ & - & $1(2.3)$ & - & $1(2)$ & \\
\hline Urine protein, $n(\%)$ & - & - & 929 & & & & \\
\hline 0 to trace $\mathrm{mg} / \mathrm{dL}$ & & - & & $803(86.4)$ & & & \\
\hline$\geq 30$ to $<100 \mathrm{mg} / \mathrm{dL}$ & & - & & $103(11.1)$ & & & \\
\hline$\geq 100$ to $<300 \mathrm{mg} / \mathrm{dL}$ & & - & & $18(1.9)$ & & & \\
\hline$\geq 300 \mathrm{mg} / \mathrm{dL}$ & & - & & $5(0.5)$ & & & \\
\hline Urine protein $\geq 30 \mathrm{mg} / \mathrm{dL}, n(\%)$ & - & - & 929 & $126(13.5)$ & & & \\
\hline
\end{tabular}

Abbreviations: $S D$ standard deviation, $n$ number of individual participants, GFR glomerular filtration rate, $B M I$ body mass index

* $P$ values indicate whether findings on Nevis versus St. Kitts were statistically significantly different

Health Organization for St. Kitts/Nevis (8\%) [2]. The World Health Organization (WHO) also reported a greater than average regional diabetes prevalence among women in St. Kitts/Nevis [3]. The mean prevalence of diabetes in the WHO Americas region is $11.5 \%$ for men and $9.9 \%$ for women [3]. According to the WHO, 14.6\% of men and $13.6 \%$ of women in St. Kitts/Nevis have diabetes [3]. It should be noted that the WHO estimates prevalence based on an elevated fasting glucose or use of medication for diabetes. The high self-reported prevalence in our sample should therefore be interpreted with caution, particularly since one screening site in St. Kitts was in close proximity to a diabetes care center. The self-reported prevalence of diabetes in St. Kitts was 23.6\%. Still, the Nevis screening center was not close to such a facility and the self-reported diabetes prevalence was still elevated at $16.8 \%$. Our ability to diagnose diabetes was limited since we were not able to measure fasting glucose or hemoglobin A1C. However, the high proportion $(8.7 \%)$ found to have a random serum glucose $\geq 200 \mathrm{mg} / \mathrm{dl}$, may provide an estimate of the level of blood glucose control in the population.

The 2008 WHO data for St. Kitts/Nevis reported $40.7 \%$ for obesity and $37.4 \%$ for hypertension [9]. These values were consistent with our screening findings. It should be noted that proportion measured to be obese in our screening program as well as the WHO data reflect a significantly greater mean than the regional Americas average (23.5\% for males and $29.7 \%$ for females) [10]. The proportion with hypertension we detected is consistent with regional estimates that reflect a significantly higher disease burden in individuals of African descent. In the US, the age-adjusted prevalence of hypertension overall is $29.1 \%$, while for black adults it is $42 \%$ [11].

There were limitations of our screening program that deserve consideration. First, we included adults who presented for screening and targeted the advertisements about our program to high-risk individuals. Further, we did not conduct population-based sampling of participants, or have an available reference point (i.e. known age/gender distribution of CKD) to which to compare our participants. Thus, we may have detected a higher proportion of individuals with CKD and its risk factors than would be obtained in a population-based sample. Second, we did not standardize the measurement of blood pressure, and therefore, measurement error was possible. Third, we were limited in our ability to administer urine albumin tests to all participants, and therefore preferentially did so among higher risk participants, which make 
Table 3 Multivariable logistic regression models of predictors of kidney disease measures among adults in St. Kitts and Nevis

\begin{tabular}{|c|c|c|c|c|}
\hline Outcome & $N$ for analysis & Variables & Odds ratio & $95 \%$ Confidence interval \\
\hline \multicolumn{5}{|l|}{ Nevis and St. Kitts Combined } \\
\hline \multirow[t]{5}{*}{ Estimated GFR $<60 \mathrm{~mL} / \mathrm{min} / 1.73 \mathrm{~m}^{2}$} & \multirow[t]{5}{*}{1978} & Age, in years & 1.08 & $1.05-1.11$ \\
\hline & & Male vs. female gender & 1.27 & $0.73-2.22$ \\
\hline & & Hypertension vs. no hypertension & 2.89 & $1.18-7.07$ \\
\hline & & Diabetes vs. no diabetes & 3.12 & $1.80-5.43$ \\
\hline & & Obesity (BMI $\geq 30$ ) vs. no obesity & 1.30 & $0.72-2.35$ \\
\hline \multicolumn{5}{|l|}{ Nevis } \\
\hline \multirow[t]{5}{*}{ Estimated GFR $<60 \mathrm{~mL} / \mathrm{min} / 1.73 \mathrm{~m}^{2}$} & \multirow[t]{5}{*}{950} & Age, in years & 1.07 & $1.04-1.10$ \\
\hline & & Male vs. female gender & 1.08 & $0.54-2.15$ \\
\hline & & Hypertension vs. no hypertension & 3.73 & $1.08-12.86$ \\
\hline & & Diabetes vs. no diabetes & 2.93 & $1.48-5.79$ \\
\hline & & Obesity (BMI $\geq 30$ ) vs. no obesity & 1.32 & $0.64-2.73$ \\
\hline \multirow[t]{5}{*}{ Albuminuria ( $\geq 30 \mathrm{mg} / \mathrm{dL}$ ) } & \multirow[t]{5}{*}{929} & Age, in years & 1.00 & $0.99-1.02$ \\
\hline & & Male vs. female gender & 1.21 & $0.81-1.83$ \\
\hline & & Hypertension vs. no hypertension & 1.34 & $0.84-2.15$ \\
\hline & & Diabetes vs. no diabetes & 2.43 & $1.53-3.87$ \\
\hline & & Obesity (BMI $\geq 30$ ) vs. no obesity & 1.06 & $0.70-1.62$ \\
\hline \multicolumn{5}{|l|}{ St. Kitts ${ }^{a}$} \\
\hline \multirow[t]{5}{*}{ Estimated GFR $<60 \mathrm{~mL} / \mathrm{min} / 1.73 \mathrm{~m}^{2}$} & \multirow[t]{5}{*}{1028} & Age, in years & 1.12 & $1.05-1.19$ \\
\hline & & Male vs. female gender & 1.57 & $0.59-4.17$ \\
\hline & & Hypertension vs. no hypertension & 1.99 & $0.53-7.49$ \\
\hline & & Diabetes vs. no diabetes & 3.62 & $1.38-9.54$ \\
\hline & & Obesity (BMI $\geq 30)$ vs. no obesity & 0.69 & $0.49-3.66$ \\
\hline
\end{tabular}

Note: All variables were simultaneously included in the models presented and were modeled as detailed Abbreviations: $B M I$ body mass index

a Predictors of proteinuria are not included for St. Kitts given the limited number of participants who underwent testing (183), and their being selected for screening due to increased risk of proteinuria

our albuminuria findings only generalizable to individuals with CKD risk factors.

\section{Conclusions}

To our knowledge this is the first report of a screening activity of this magnitude for CKD in the Caribbean. This first effort lays the ground work for developing health strategies for prevention and treatment of CKD and ESRD and their risk factors in St. Kitts and Nevis, diseases of which are associated with high cost, morbidity and mortality. Development of public health strategies to improve access to primary care, treatment of conditions such as diabetes and hypertension, increasing public health awareness of obesity and increasing awareness of the benefits of lifestyle changes, as well as education of primary care providers as to how to assess, treat, and intervene on their patients for these most prevalent causes of CKD/ESRD, are specific recommendations that may help to eventually decrease the incidence of CKD and ESRD in St. Kitts and Nevis.

\section{Abbreviations}

CHEF: Caribbean Health and Education Foundation; Cl: Confidence interval: CKD: Chronic kidney disease; CKSEP: Caribbean Kidney Screening and Education Program; CME: Continuing medical education; CRR: Caribbean Renal Registry; EGFR: Estimated glomerular filtration rate; ESRD: End stage renal disease; IRB: Institutional Review Board; NIDDK: National Institute for Diabetes and Digestive and Kidney Diseases; OR: Odds ratio; WHO: World Health Organization

\section{Acknowledgments \\ None.}

\section{Funding}

This work was supported by the Caribbean Health and Education Foundation (CHEF), Abbott Laboratories, Henry Schein Cares Foundation and the DaVita Village Trust Foundation. O.D. and I.D. are employed by CHEF and contributed to the design of the study and collection, analysis, and interpretation of data and in writing the manuscript. Abbott Laboratories nor Henry Schein Cares Foundation were involved in the design of the study, or collection, analysis, or interpretation of data; and were not involved in writing the manuscript. The DaVita Village Trust Foundation were involved in the collection of data, but not in the design of the study, analysis, or interpretation of data; and were not involved in writing the manuscript. D.C.C. was supported by grant K23 DK097184 and B.A.Y. was supported by grant DK 1R01DK102134-01 from the National Institute of Diabetes and Digestive and Kidney Diseases (NIDDK), National Institutes of Health, Bethesda, Maryland USA. B.A.Y. was also supported 
in part by funding from the Veterans Affairs Puget Sound Health Care System. The Veterans Affairs does not endorse any of the statements or opinions advocated by this manuscript. NIDDK nor the Veterans Affairs were involved in the design of the study, or collection, analysis, or interpretation of data; and were not involved in writing the manuscript.

\section{Availability of data and materials}

The datasets generated during and/or analyzed during the current study are not publicly available due to an agreement with the Ministry of Health of St. Kitts and Nevis but are available from the corresponding author on reasonable request.

\section{Authors' contributions}

$\mathrm{DCC}, \mathrm{KNC}, \mathrm{OD}, \mathrm{ID}$ and BAY participated in the design and conduct of the study and contributed to the drafting of the manuscript. YL performed the statistical analyses for the study and drafted portions of the manuscript. All authors read and approved the final manuscript.

\section{Competing interests}

The authors declare that they have no competing interests. D.C.C. is an Editorial Board member of BMC Nephrology but took no part in the peer-review of this submission.

\section{Consent for publication}

Not applicable.

\section{Ethics approval and consent to participate}

The study protocol was approved by the Ministry of Health \& Social Services of the Government of Saint Christopher (Saint Kitts) and Nevis, and by the Johns Hopkins University School of Medicine Institutional Review Board (IRB) and all procedures followed were in accordance with the ethical standards of the IRB and the Helsinki Declaration of 1975, as revised in 2000. All participants provided written consent.

\section{Author details}

'Division of Nephrology, Department of Medicine, Johns Hopkins University School of Medicine, 301 Mason F. Lord Drive, Suite 2500, Baltimore, MD 21224, USA. ${ }^{2}$ Welch Center for Prevention Epidemiology and Clinical Research, Johns Hopkins Medical Institutions, Baltimore, MD, USA. ${ }^{3}$ Division of Nephrology, Department of Medicine, Icahn School of Medicine at Mount Sinai, New York, NY, USA. ${ }^{4}$ Caribbean Health and Education Foundation, Takoma Park, MD, USA. ${ }^{5}$ Division of Nephrology, Department of Medicine Seattle Puget Sound Veterans Affairs, Kidney Research Institute, University of Washington at Seattle, Seattle, WA, USA.

Received: 20 July 2016 Accepted: 20 December 2016

Published online: 05 January 2017

\section{References}

1. Caribbean Epidemiology Centre PAHO/WHO Epidemiology Division. Leading causes of death and mortality rates. 2000. http://carpha.net/pdf/ Mortality_Final_LR\%20_\%20061205.pdf. Accessed 15 July 2014.

2. Soyibo AK, Roberts $L$, Barton EN. Chronic kidney disease in the Caribbean. West Indian Med J. 2011;60(4):464-70.

3. Soyibo AK, Barton EN. Chronic renal failure from the English-speaking Caribbean: 2007 data. West Indian Med J. 2009;58(6):596-600.

4. Levey AS, Bosch JP, Lewis JB, Greene T, Rogers N, Roth D. A more accurate method to estimate glomerular filtration rate from serum creatinine: a new prediction equation. Modification of Diet in Renal Disease Study Group. Ann Intern Med. 1999;130(6):461-70.

5. K/DOQI clinical practice guidelines for chronic kidney disease: evaluation, classification, and stratification. Am J Kidney Dis. Feb 2002; 39(2 Suppl 1):S1-266.

6. Saudek CD, Herman WH, Sacks DB, Bergenstal RM, Edelman D, Davidson MB. A new look at screening and diagnosing diabetes mellitus. J Clin Endocrinol Metab. 2008;93(7):2447-53.

7. James PA, Oparil S, Carter BL, et al. 2014 evidence-based guideline for the management of high blood pressure in adults: report from the panel members appointed to the Eighth Joint National Committee (JNC 8). JAMA. 2014;311(5):507-20.
8. Soyibo AK, Barton EN. Report from the Caribbean renal registry, 2006. West Indian Med J. 2007:56(4):355-63.

9. World Health Organization. St. Kitts Health Profile. http://www.who.int/gho/ countries/kna/en/. Accessed 15 July 2014

10. Pan-American Health Organization-St. Kitts/Nevis Country Health Profile 2012. http://www1.paho.org/English/DD/AIS/cp_659.htm. Accessed 15 July 2014

11. Nwankwo T, Yoon SS, Burt V, Gu Q. Hypertension among adults in the United States. National Health and Nutrition Examination Survey, 2011-2012. NCHS Data Brief. 2013;133:1-8.

\section{Submit your next manuscript to BioMed Central and we will help you at every step:}

- We accept pre-submission inquiries

- Our selector tool helps you to find the most relevant journal

- We provide round the clock customer support

- Convenient online submission

- Thorough peer review

- Inclusion in PubMed and all major indexing services

- Maximum visibility for your research

Submit your manuscript at www.biomedcentral.com/submit
) Biomed Central 